Full Length Article

\title{
Phase equilibrium data and modeling of ethylic biodiesel, with application to a non-edible vegetable oil
}

\author{
Fahad Muhammad $^{\mathrm{a}, \mathrm{b}}$, Mariana B. Oliveira ${ }^{\mathrm{c}}$, Patrice Pignat ${ }^{\mathrm{d}}$, Jean-Noël Jaubert ${ }^{\mathrm{b}}$, Simão P. Pinho ${ }^{\mathrm{a}, *}$, \\ Lucie Coniglio ${ }^{\mathrm{b}, *}$ \\ a Associate Laboratory LSRE-LCM, Instituto Politécnico de Bragança, Campus de Santa Apolónia, 5300-253 Bragança, Portugal \\ ${ }^{\mathrm{b}}$ Université de Lorraine - ENSIC, Laboratoire Réactions et Génie des Procédés (UMR CNRS 7274), 1 rue Grandville, 54000 Nancy, France \\ ${ }^{\mathrm{c}}$ CICECO - Aveiro Institute of Materials, Chemistry Department, University of Aveiro, 3810-193 Aveiro, Portugal \\ ${ }^{\mathrm{d}}$ PIGNAT SAS, 6, rue Calmette, 69740 Genas, France
}

\section{A R T I C L E I N F O}

\section{Article history:}

Received 5 April 2017

Received in revised form 29 April 2017

Accepted 2 May 2017

Available online 10 May 2017

\section{Keywords:}

Vapor-liquid equilibrium

Biodiesel

Consistency

CPA

UNIFAC

NEVO

\begin{abstract}
A B S T R A C T
Contributing to extending the knowledge for the design and operation of biodiesel production processes, isobaric PTxy vapor-liquid equilibria data of ethanol + ethyl hexanoate, 1-pentanol + ethyl hexanoate and 1-pentanol + ethyl octanoate at two different pressures are reported for the first time. Consistency tests were applied to attest the quality of the collected data, for these especially complex measurements. Besides that, vapor pressures of the pure ethyl esters have also been measured. For modeling purposes, the Lyngby and Dortmund UNIFAC variants were used to predict the VLE phase diagrams. Generally, the predictions are of very good quality, being the UNIFAC-Do (Dortmund) better, as the deviations in temperature and vapor compositions are always lower to $1.0 \mathrm{~K}$ and 0.020 , respectively. Checking for the viability for extrapolations in pressure, CPA EoS was also applied to the modeling of the experimental data with very good results. Finally, aiming at examining the model capabilities to describe multicomponent systems, VLE measurements involving two alcohols and the fatty acid ethyl ester mixture obtained from non-edible vegetable oil have been carried out showing the good performance of the predictive models.
\end{abstract}

(c) 2017 Elsevier Ltd. All rights reserved.

\section{Introduction}

The ever increasing worldwide concern for environmental protection and for the conservation of non-renewable natural resources have led to the development of fatty acid esters as diesel substitutes, known as biodiesel [1]. For a rational design and operation of biodiesel production processes, it is essential to have quantitative and reliable information about the vapor-liquid equilibrium (VLE) and liquid-liquid equilibrium of mixtures containing alcohols, fatty acid esters or glycerol. However, experimental data for many of theses systems is still missing [2]. In 2014 the extended review by Coniglio et al. [2] highlighted the great lack of data, while in the work by Cunico et al. [3], from the same year, a comprehensive application of thermodynamic consistency tests for VLE over systems containing the main classes of compounds present in the biodiesel production, showed that only $3 \%$ of the data sets had quality factors higher than 0.5 (maximum is 1.0) [3].

\footnotetext{
* Corresponding authors.

E-mail addresses: spinho@ipb.pt (S.P. Pinho), lucie.coniglio@univ-lorraine.fr (L. Coniglio).
}

These works [2,3] strongly suggested the need of more precise and consistent measurements that can be used to test and develop models for the design and operation of the biodiesel production processes. Among those, conventional excess Gibbs energy models such as Wilson, NRTL, and UNIQUAC equations, group-contribution approaches of the UNIFAC family, but also equations of state (EoS) like CPA, Peng-Robinson, SAFT have been applied [2,4,5], but further developments are still needed. In particular, due to the real competition of edible oils for human nutrition, non-edible vegetable oils (NEVO) are becoming one of the leading raw materials for biodiesel production, for which fundamental and application studies are extremely necessary. The oil based on Balanites aegyptiaca (BA) $[6,7]$ is well characterized, containing mostly the fatty acids C16 and C18, with a well-known impact on fuel properties. Moreover, the BA oil quality parameters are quite similar to those of soy oil, which is one of the most used for biodiesel production. In addition, ethyl esters of BA oil showed cleaner combustion than petrodiesel [8]. This suggests that BA can be an attractive alternative for sustainable biodiesel production.

Therefore, the aim of this work is to deliver a large body of consistent and complete experimental VLE data for compounds, and mixtures, of relevance in the biofuel industry. Besides that, 
group-contribution approaches and Cubic-Plus-Association (CPA) equation of state (EoS) are evaluated for their predictive capabilities, not only in binary mixtures, but perhaps more importantly over a multicomponent mixture containing alcohols and ethyl esters synthesized from BA oil.

\section{Material and methods}

\subsection{Chemicals}

The list of chemicals used in this work is given in Table 1 along with supplier and purity. These chemicals were used as received without any further purification.

\subsection{Production of BAEEs}

Balanites aegyptiaca oil was obtained by extraction, i.e. simultaneous cold pressing and filtration of the seed kernels collected from trees growing in arid and semi-arid regions of Burkina Faso $[6,7]$. The BA ethyl esters (BAEEs) were synthesized via alkali catalysis $(\mathrm{KOH})$, under a two-stage procedure based on intermediate addition of glycerol. Alkali catalysis was operated at $35^{\circ} \mathrm{C}$, with an ethanol to oil molar ratio equal to $8: 1$, a catalyst concentration of $1 \mathrm{wt} \%$ based on the initial mass of oil, and a reaction time of $50 \mathrm{~min}$, while the addition of glycerol marking the start of the second step was carried out after 30 min of reaction. The ester content of the BAEEs yielded $97 \%$ on weigh basis. The resulting ethyl esters are later purified by the dry-washing method conducted in batch mode, using $4 \mathrm{wt} \%$ of rice husk ash, which were mixed and stirred continuously for $20 \mathrm{~min}$ and heated at $35^{\circ} \mathrm{C}$. A vacuum distillation (180-200 ${ }^{\circ} \mathrm{C} ; 10 \mathrm{mbar}$ ) was finally carried out in order to insure a high grade level of the BAEE mixture used afterwards for VLE study. The BAEE final composition and details of the analytical method [9] used to obtain it are presented in Supplementary Material, SM1 and SM2, respectively.

\subsection{VLE apparatus and measurements}

The VLE experiments were performed by using an all-glass dynamic recirculating ebulliometer, model EEA 3000 manufactured by Pignat Company (France), represented in Fig. S1 of SM3 [10]. This device is equipped with a Cottrell circulation pump that promotes a vigorously mixing of liquid and vapor phases. The adiabaticity of the equilibrium chamber (1) is attained by vacuum with a silver wall having an outlet temperature $(\mathrm{TI} / 02)$ from the vapor-liquid outlet of the Cottrell pump. The vapor phase is condensed (3) and sent by gravity into the buffer cell (6) equipped with a magnetic stirrer, while the liquid phase is fed directly by gravity in the same buffer cell. The two mixed phases are then recycled to the boiler (2). The samples are taken from the two sampling outlets by collecting them in a test tube fitted on the return

Table 1

Source and purity of compounds used in this study.

\begin{tabular}{lllc}
\hline Chemical name & CAS & Source & Purity/mol \% \\
\hline Ethanol & $64-17-5$ & Sigma Aldrich & $\geq 99.8$ \\
1-Butanol & $71-36-3$ & Fluka & $\geq 99.5$ \\
1-Pentanol & $71-41-0$ & Sigma Aldrich & $\geq 99$ \\
1-Octanol & $111-87-5$ & Sigma Aldrich & $\geq 99$ \\
1-Decanol & $112-30-1$ & Fluka & $\geq 99.5$ \\
1-Dodecanol & $112-53-8$ & Sigma Aldrich & $\geq 98$ \\
Ethyl hexanoate & $123-66-0$ & Sigma Aldrich & $\geq 99$ \\
Ethyl octanoate & $106-32-1$ & Sigma Aldrich & $\geq 99$ \\
Ethyl oleate & $111-62-6$ & Sigma Aldrich & $\geq 98$ \\
Methyl heptadecanoate & $1731-92-6$ & Fluka & $\geq 99$ \\
Potassium hydroxide & $1710-58-3$ & Fluka & $\geq 85$ \\
\hline
\end{tabular}

circuits of condensed vapor and liquid phases, upstream of the buffer cell. The vacuum circuit (4) consists of two solenoid valve pressure control systems (EV1 and EV2). A dry ice trap (7) is also available at the top of the equipment to protect the pressure sensor (PIC/01) from contact with the fluids being studied, but is also needed for precise measurements under atmospheric pressure. The uncertainty of the temperature sensor is $\pm 0.01 \mathrm{~K}$, while pressure sensor presents an uncertainty of $\pm 0.013 \mathrm{kPa}( \pm 0.1 \mathrm{mmHg})$.

Initially, the sensors accuracy was analyzed calibrating the temperature sensor in the ebulliometer using a reference thermometer, and measuring the vapor pressure at different temperatures for ethanol selected as reference compound (green species with well-known properties in a large temperature range). After, the vapor pressures of some pure ethyl esters to be studied in binary and multicomponent mixtures are determined using the dynamic ebulliometer. The measurement of vapor pressure serves two guiding purposes: to check the calibration of the equipment and to extend considerably the available vapor pressure data for the studied compounds.

For the isobaric VLE measurements the more volatile compound is initially introduced into the boiler (2) via the funnel (5). A portion of the liquid is evaporated in the boiler by means of an electrical resistance of $500 \mathrm{~W}$, and the system let to equilibrate. The equilibrium state, commonly reached in 0.5 to $1 \mathrm{~h}$ of recirculating, is identified when steady temperature is observed for the selected set-point pressure, leading then to assume that composition of both the liquid and vapor phases is also constant. Then, the equilibrium temperature is noted down and samples are collected simultaneously from the liquid and vapor phases for quantification. The less volatile component (esters) are after introduced through funnel (5) in amounts equivalent to the quantity removed from the ebulliometer in the form of vapor and liquid samples. This procedure is continued until the samples in both the liquid and vapor phases finally result in pure ester, signifying the end of the equilibrium diagram. This is perceptible as the temperature of the ebulliometer reaches a constant value, and the addition of more esters has an insignificant effect on the equilibrium temperature and the composition of both phases. For each binary system two different set-point pressures are studied.

\subsection{Analytical method}

All collected samples were analyzed in an Agilent Technology gas chromatograph coupled with a flame ionization detector (GCFID). Details of the equipment, operating conditions and calibration are given in SM2. The temperature programs selected for the GC-column and the internal standard (IS) selected for calibration were adapted to the analyzed mixture. For all investigated systems, two ISs were used to determine the collected sample composition (one for the alcohol(s) and the other one for the ester(s)). Preliminary GC-FID calibration was carried out with standard solutions of well-known composition in the two ISs and components of the studied system, prepared over the full range of composition. Calibration performance was then checked by preparing supplementary standard solutions with intermediary compositions in the system components. This last stage allowed for estimating the composition uncertainty ranging from \pm 0.001 for the binary systems to \pm 0.004 for the mixtures involving BAEEs.

\section{Results and discussion}

\subsection{Pure component vapor pressure}

After the calibration procedure, the equipment was tested to measure the vapor pressure of ethanol. The experimental values 
are presented in Table S3, and a comparison with those calculated from the DIPPR database [11] is given in Fig. S2 of SM4. In this plot the percentage relative deviation is shown for each experimental point, varying from $-0.2 \%$ up to $0.2 \%$, exhibiting also a random distribution, while the average relative deviation is about $0.1 \%$, which is lower than the values usually found $[12,13]$ and gives a good indication about the quality of the vapor pressure measured in this work. The equation applied in the vapor pressure calculation is:

$\ln \left(P_{i}^{S} / P a\right)=A_{i}+\frac{B_{i}}{(T / K)}+C_{i} \ln (T / K)+D_{i}(T / K)^{E_{i}}$

where $T$ is the absolute temperature, and $P_{i}^{S}$ the vapor pressure of compound $i$. Table S4 of SM4 presents the coefficients $\left(A_{i}\right.$ to $\left.E_{i}\right)$ found in the DIPPR database [11].

The measured pure component vapor pressures of two fatty acid ethyl esters (FAEEs), ethyl hexanoate and ethyl octanoate, are also presented in Table S3. It must be mentioned that for some substances the number of data available in the open literature is really small, like for ethyl octanoate for which only 48 data points are registered in the Dortmund databank [14].

Available data for FAEEs are insufficient to check their validity as done for ethanol. Alternatively, the data discrimination method of Wilsak and Thodos $[15,16]$ is here applied. As briefly presented in the SM5, the data can be considered of good quality if the $\delta$ values are placed on a smooth concave curve as can be seen for both compounds in Fig. 1. Moreover, the difference between the $\delta$ values at the same temperature, gives the relative deviation between two sets of data, which is generally lower than $4 \%$.

\subsection{Binary systems}

The isobaric VLE data measured for ethanol + ethyl hexanoate binary system at 40 and $53.33 \mathrm{kPa}$ are presented in Table 2, where besides temperature, the liquid $(x)$ and vapor $(y)$ equilibrium mole fraction compositions are given. The two substances present very different boiling points, which makes the VLE measurements pretty demanding. On the contrary, 1-pentanol and ethyl hexanoate have very close boiling points, and the VLE behavior for this system was studied at 14.65 and $40 \mathrm{kPa}$ as indicated in Table 3 . Finally, Table 4 compiles the VLE data for the system 1-pentanol + ethyl octanoate at 15 and $40 \mathrm{kPa}$. All mixtures studied are zeotropic.

For sub-atmospheric conditions, the activity coefficients of each compound $i\left(\gamma_{\mathrm{i}}\right)$ in the mixture at the equilibrium pressure $P$ can be calculated by:

$\gamma_{i}=\frac{y_{i} P}{x_{i} P_{i}^{S}}$

A moderate positive deviation from ideal behavior was observed for all systems, as previously found for similar alcohol + ester binary systems $[13,20]$, more evident as the difference between the carbon number in the alcohol and ester increases. Though esters are not able to self-associate, cross association
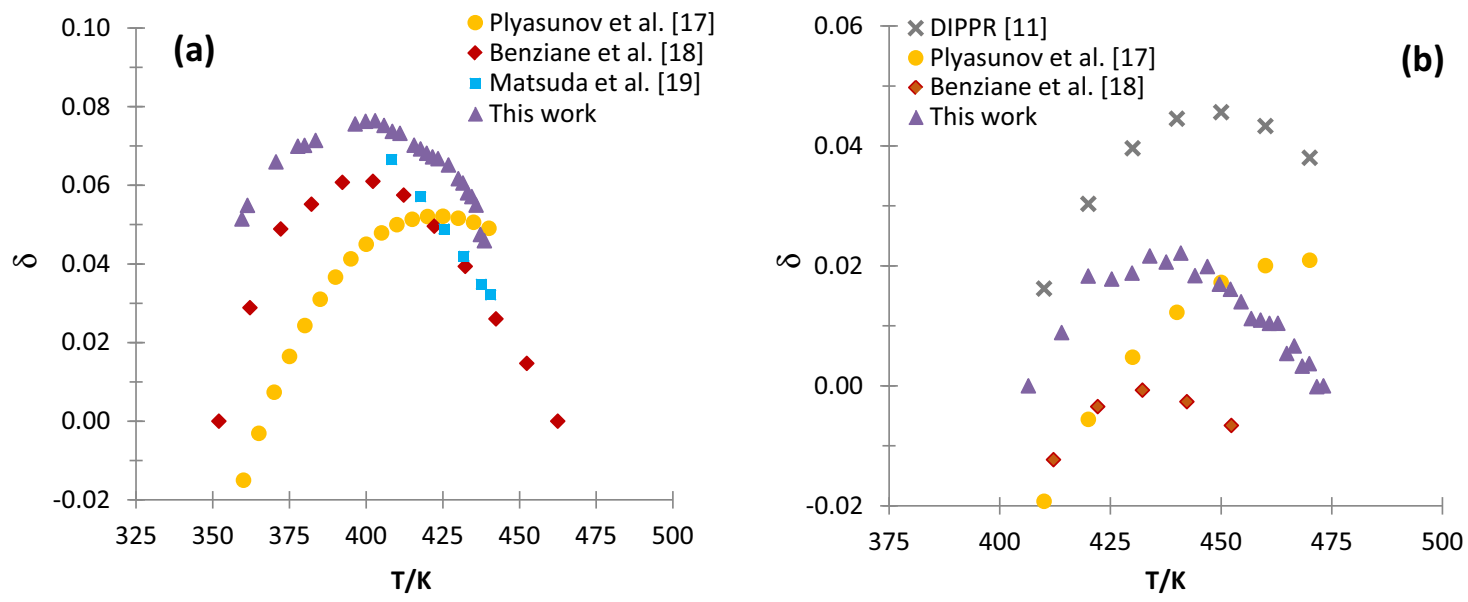

Fig. 1. Vapor pressure analysis for ethyl hexanoate (a) and ethyl octanoate (b) by the Wilsak and Thodos method [11,15-19].

Table 2

Isobaric VLE data for ethanol (1) + ethyl hexanoate (2) system. ${ }^{\text {a }}$

\begin{tabular}{|c|c|c|c|c|c|}
\hline \multicolumn{3}{|c|}{$40.00 \mathrm{kPa}$} & \multicolumn{3}{|c|}{$53.33 \mathrm{kPa}$} \\
\hline$T(\mathrm{~K})$ & $x_{1}$ & $y_{1}$ & $T(\mathrm{~K})$ & $x_{1}$ & $y_{1}$ \\
\hline 329.58 & 1.0000 & 1.0000 & 335.98 & 1.0000 & 1.0000 \\
\hline 331.08 & 0.9091 & 0.9892 & 337.68 & 0.9014 & 0.9889 \\
\hline 332.48 & 0.8115 & 0.9819 & 338.88 & 0.8218 & 0.9823 \\
\hline 334.18 & 0.6874 & 0.9743 & 340.58 & 0.7144 & 0.9755 \\
\hline 336.58 & 0.5223 & 0.9663 & 343.08 & 0.5653 & 0.9669 \\
\hline 338.98 & 0.4317 & 0.9588 & 346.48 & 0.4283 & 0.9553 \\
\hline 341.68 & 0.3439 & 0.9487 & 350.19 & 0.3130 & 0.9408 \\
\hline 348.29 & 0.2284 & 0.9210 & 356.49 & 0.2421 & 0.9164 \\
\hline 357.49 & 0.1423 & 0.8723 & 362.79 & 0.1624 & 0.8816 \\
\hline 373.29 & 0.0710 & 0.7334 & 369.39 & 0.1179 & 0.8408 \\
\hline 384.60 & 0.0402 & 0.5740 & 388.70 & 0.0586 & 0.6535 \\
\hline 400.10 & 0.0166 & 0.2011 & 402.81 & 0.0323 & 0.3806 \\
\hline 408.02 & 0.0000 & 0.0000 & 417.31 & 0.0000 & 0.0000 \\
\hline
\end{tabular}

${ }^{\text {a }}$ Experimental uncertainties $u$ are: $u(T)=0.01 \mathrm{~K}, u(P)=0.013 \mathrm{kPa}, u\left(x_{1}\right)=u\left(y_{1}\right)=0.001$. 
Table 3

Isobaric VLE data for 1-pentanol (1) + ethyl hexanoate (2) system. ${ }^{\mathrm{a}}$

\begin{tabular}{|c|c|c|c|c|c|}
\hline \multicolumn{3}{|c|}{$14.65 \mathrm{kPa}$} & \multicolumn{3}{|c|}{$40.00 \mathrm{kPa}$} \\
\hline$T(\mathrm{~K})$ & $x_{1}$ & $y_{1}$ & $T(\mathrm{~K})$ & $x_{1}$ & $y_{1}$ \\
\hline 361.83 & 1.0000 & 1.0000 & 385.15 & 1.0000 & 1.0000 \\
\hline 362.23 & 0.9051 & 0.9215 & 386.05 & 0.8620 & 0.9124 \\
\hline 362.23 & 0.8829 & 0.9059 & 386.95 & 0.7845 & 0.8554 \\
\hline 362.73 & 0.8226 & 0.8616 & 388.05 & 0.6845 & 0.7953 \\
\hline 362.83 & 0.8019 & 0.8497 & 389.55 & 0.5784 & 0.7306 \\
\hline 363.43 & 0.7081 & 0.7906 & 390.65 & 0.4987 & 0.6846 \\
\hline 363.53 & 0.6826 & 0.7786 & 393.35 & 0.3923 & 0.5889 \\
\hline 364.43 & 0.5869 & 0.7237 & 395.56 & 0.3041 & 0.5042 \\
\hline 364.43 & 0.5819 & 0.7199 & 397.86 & 0.2390 & 0.4160 \\
\hline 365.43 & 0.5081 & 0.6677 & 401.06 & 0.1463 & 0.2971 \\
\hline 365.43 & 0.4918 & 0.6675 & 403.26 & 0.0938 & 0.2068 \\
\hline 366.53 & 0.4122 & 0.6122 & 404.36 & 0.0708 & 0.1580 \\
\hline 366.63 & 0.4026 & 0.6045 & 408.07 & 0.0000 & 0.0000 \\
\hline 368.23 & 0.3121 & 0.5330 & & & \\
\hline 369.34 & 0.2660 & 0.4876 & & & \\
\hline 371.13 & 0.1963 & 0.3999 & & & \\
\hline 371.34 & 0.1944 & 0.3931 & & & \\
\hline 374.14 & 0.1204 & 0.2683 & & & \\
\hline 374.63 & 0.1033 & 0.2426 & & & \\
\hline 375.64 & 0.0785 & 0.1967 & & & \\
\hline 379.14 & 0.0000 & 0.000 & & & \\
\hline
\end{tabular}

a Experimental uncertainties $u$ are: $u(T)=0.01 \mathrm{~K}, u(P)=0.013 \mathrm{kPa}, u\left(x_{1}\right)=u\left(y_{1}\right)=0.001$.

Table 4

Isobaric VLE data for 1-pentanol (1) + ethyl octanoate (2) system. ${ }^{\text {a }}$

\begin{tabular}{|c|c|c|c|c|c|}
\hline \multicolumn{3}{|c|}{$15.00 \mathrm{kPa}$} & \multicolumn{3}{|c|}{$40.00 \mathrm{kPa}$} \\
\hline$T(\mathrm{~K})$ & $x_{1}$ & $y_{1}$ & $T(\mathrm{~K})$ & $x_{1}$ & $y_{1}$ \\
\hline 362.33 & 1.0000 & 1.0000 & 385.05 & 1.0000 & 1.0000 \\
\hline 363.73 & 0.9247 & 0.9853 & 387.05 & 0.8827 & 0.9792 \\
\hline 364.93 & 0.8574 & 0.9737 & 389.75 & 0.7835 & 0.9609 \\
\hline 365.63 & 0.8203 & 0.9676 & 389.85 & 0.7904 & 0.9611 \\
\hline 366.63 & 0.7672 & 0.9584 & 391.45 & 0.7180 & 0.9482 \\
\hline 367.63 & 0.7126 & 0.9495 & 392.15 & 0.6858 & 0.9436 \\
\hline 368.43 & 0.6667 & 0.9421 & 394.15 & 0.6149 & 0.9276 \\
\hline 369.74 & 0.6124 & 0.9335 & 394.45 & 0.5996 & 0.9258 \\
\hline 369.94 & 0.5976 & 0.9298 & 396.46 & 0.5327 & 0.9087 \\
\hline 373.14 & 0.4832 & 0.9028 & 397.06 & 0.4947 & 0.9002 \\
\hline 373.44 & 0.4768 & 0.9002 & 400.46 & 0.4340 & 0.8773 \\
\hline 376.84 & 0.3741 & 0.8704 & 401.16 & 0.4125 & 0.8700 \\
\hline 377.74 & 0.3561 & 0.8613 & 407.06 & 0.3139 & 0.8140 \\
\hline 380.44 & 0.2948 & 0.8300 & 407.56 & 0.2973 & 0.8144 \\
\hline 384.15 & 0.2380 & 0.7893 & 414.37 & 0.2214 & 0.7300 \\
\hline 384.95 & 0.2235 & 0.7782 & 415.28 & 0.2043 & 0.7232 \\
\hline 396.26 & 0.1138 & 0.5917 & 425.28 & 0.1192 & 0.5652 \\
\hline 397.26 & 0.1058 & 0.5745 & 426.68 & 0.1119 & 0.5552 \\
\hline 404.76 & 0.0553 & 0.3885 & 437.79 & 0.0479 & 0.2791 \\
\hline 405.96 & 0.0509 & 0.3590 & 438.69 & 0.0404 & 0.2505 \\
\hline 416.27 & 0.0000 & 0.0000 & 446.39 & 0.0000 & 0.0000 \\
\hline
\end{tabular}

a Experimental uncertainties $u$ are: $u(T)=0.01 \mathrm{~K}, u(P)=0.013 \mathrm{kPa}, u\left(x_{1}\right)=u\left(y_{1}\right)=0.001$.

between the ester and the hydroxyl groups exists, that somehow brings some light to the fact that the alcohol activity coefficient at infinite dilution is close to 1 (Table S5, SM6).

\subsubsection{Thermodynamic consistency}

For the system ethanol + ethyl hexanoate, VLE data have been measured by Matsuda et al. [19] at the same pressures, which will be briefly compared in the next section. More adequately, the quality of the experimental data was analyzed by applying a quality assessment algorithm for VLE data proposed by Kang et al. $[21,22]$. Four consistency tests were combined: the Herington test, the Van Ness test, the infinite dilution test, and the pure component test [21-26]. For each test, a quality factor $F_{\text {test }}$ was calculated. The maximum value is 1.0 for the pure component test and 0.25 for the remaining three tests. Then, for each VLE data set, an overall quality factor $\left(Q_{V L E}\right)$ can be calculated as follows $[12,21]$ :
$Q_{V L E}=F_{\text {purecomponent }} \cdot\left(F_{\text {Herington }}+F_{\text {vanNess }}+F_{\text {Infinitedilution }}\right) / 0.75$

The quality factors are shown in Table 5, attaining the maximum value for the ethanol + ethyl hexanoate binary mixture. For the remaining systems, the overall quality factors are between 0.27 and 0.61 , which are very satisfactory as Cunico et al. [3] reports that for systems with fatty esters, fatty acids, among other components relevant in the biofuel industry, only $3 \%$ of the data sets presents an overall quality factor higher than 0.5 , with an average of 0.23 among 92 VLE data sets, while in this work the average is 0.56 .

Also interesting to note is that in some systems such as 1pentanol + ethyl octanoate, the alcohol activity coefficient calculated from the experimental data shows a maximum for alcohol mole fraction close to 0.20 (Fig. S3 of SM6). This strongly contributes for the small quality factor for the infinite dilution test. In this test, the infinite dilution activity coefficients are estimated 
Table 5

Consistency test results for all the binary systems.

\begin{tabular}{|c|c|c|c|c|c|}
\hline Pressure & Herington & van Ness & Infinite Dilution & Pure & Overal \\
\hline \multicolumn{6}{|c|}{ Ethanol-Ethyl hexanoate } \\
\hline $40 \mathrm{kPa}$ & 0.20 & 0.25 & 0.14 & 1.00 & 0.79 \\
\hline $53.33 \mathrm{kPa}$ & 0.16 & 0.25 & 0.25 & 1.00 & 0.88 \\
\hline \multicolumn{6}{|c|}{ 1-Pentanol-Ethyl hexanoate } \\
\hline $14.65 \mathrm{kPa}$ & 0.07 & 0.25 & 0.14 & 1.00 & 0.61 \\
\hline $40 \mathrm{kPa}$ & 0.04 & 0.25 & 0.04 & 0.61 & 0.27 \\
\hline \multicolumn{6}{|c|}{ 1-Pentanol-Ethyl octanoate } \\
\hline $15 \mathrm{kPa}$ & 0.25 & 0.25 & 0.05 & 0.55 & 0.40 \\
\hline $40 \mathrm{kPa}$ & 0.25 & 0.25 & 0.05 & 0.55 & 0.40 \\
\hline
\end{tabular}

from experimental data either using the excess Gibbs energy function or the natural logarithm of activity coefficient ratio and compared, which can give very different results in the case of the alcohol (see Table S5 of SM6), and makes the quality factor much lower when the alcohol activity coefficient at infinite dilution estimated from $\ln \left(\gamma_{1} / \gamma_{2}\right)$ is close to one. It is also relevant to mention that for the system 1-pentanol + ethyl octanoate, the quality factor $F_{\text {pure }}$ reduces considerably the overall quality factor, most probably because the vapor pressure of pure ethyl octanoate is not so well established in the literature.

\subsubsection{Thermodynamic modeling}

The experimental data were correlated using the NRTL activity coefficient model [27] with a temperature dependence given in SM7. The binary interaction parameters were estimated by the least-squares method, by minimizing the following objective function $F_{o b j}$ :

$F_{o b j}=\sum_{i=1}^{N}\left(\frac{P_{i}^{\text {calc }}-P_{i}^{\text {exp }}}{P_{i}^{\exp }}\right)^{2}$

where $N$ is the number of experimental points, and the superscripts "calc" and "exp" represent calculated and experimental values, respectively. Table S6 (SM7) presents the obtained binary interaction parameters.

Predictive group-contribution activity coefficient methods, namely Lyngby modified UNIFAC [28] and Dortmund modified UNIFAC [29-33] were also evaluated. The identification and number of groups considered in each component are given in Table S7 (SM7).

Model performance is evaluated in terms of average deviations in temperature and vapor phase composition (of the alcohol) for each isobaric VLE data set as given in Table 6. The deviations show that all systems are very satisfactorily described by the different models but, due to its correlative nature, NRTL performs much bet- ter than others. Observing Fig. 2a, in the system ethanol + ethyl hexanoate the pure predictive Dortmund modified UNIFAC (UNIFAC-Do) model performs as good as the NRTL correlative model, as can be inferred by the correspondent overlapping curves, while in the system 1-pentanol + ethyl hexanoate, both predictive approaches show higher deviations than NRTL, in particular concerning the boiling curve (Fig. 2b). In fact, in all systems studied higher deviations are observed when the liquid phase is rich in the ester, as can be easily understood comparing the calculated and experimental activity coefficients (Fig. S3, SM6). Nevertheless, UNIFAC-Do gives always better results than Lyngby modified UNIFAC (UNIFAC-Ly), and can be used as a predictive tool.

Like mentioned in section 3.2.1 a comparison between the data measured in this work, for the binary system ethanol + ethyl hexanoate, and from Matsuda et al. [19] is given in Figs. $2 a$ and 3. These authors did not measure the vapor phase composition, but Figs. 2a and 3 clearly show an evident deviation in the boiling temperatures when the liquid phase is richer in ethyl hexanoate if compared to results collected in this work, a deviation which is also observed when comparing Matsuda et al. [19] experimental data to all predicted results.

The use of high pressures for the synthesis of biodiesel is envisaged for real plants. Therefore, testing the features of an equation of state like CPA in the calculation of the VLE diagram is of enormous relevance. The compounds of the ester family are non-selfassociating (only three pure compound parameters) while alcohols are considered as having two association sites and species for which the $2 \mathrm{~B}$ association scheme applies (five pure compound parameters). The set of parameters for the selected compounds for this work were already previously established in the open literature [34-36] and are presented at Table S8 (SM7).

The cross-association between the ester group and the hydroxyl group for the systems here selected needs to be explicitly taken accounted for, as previously done when studying and describing the VLE of several ester + methanol/ethanol systems [37], by using

Table 6

Average temperature and vapor composition deviations* using NRTL, UNIFAC-Ly, UNIFAC-Do, and CPA EoS.

\begin{tabular}{|c|c|c|c|c|c|c|c|c|}
\hline \multirow[t]{3}{*}{ Pressure (kPa) } & \multicolumn{8}{|l|}{ Model } \\
\hline & \multicolumn{2}{|l|}{ NRTL } & \multicolumn{2}{|c|}{ UNIFAC-Ly } & \multicolumn{2}{|c|}{ UNIFAC-Do } & \multicolumn{2}{|l|}{ CPA } \\
\hline & $\Delta T(\mathrm{~K})$ & $\Delta y_{1}$ & $\Delta T(\mathrm{~K})$ & $\Delta y_{1}$ & $\Delta T(\mathrm{~K})$ & $\Delta y_{1}$ & $\Delta T(\mathrm{~K})$ & $\Delta y_{1}$ \\
\hline \multicolumn{9}{|c|}{ Ethanol (1) + Ethyl hexanoate (2) } \\
\hline 40.00 & 0.41 & 0.007 & 2.20 & 0.020 & 0.39 & 0.010 & 2.31 & 0.030 \\
\hline 53.33 & 0.34 & 0.004 & 2.50 & 0.020 & 0.94 & 0.010 & 2.58 & 0.024 \\
\hline \multicolumn{9}{|c|}{ 1-Pentanol (1) + Ethyl hexanoate (2) } \\
\hline 14.65 & 0.19 & 0.007 & 0.84 & 0.010 & 0.64 & 0.010 & 0.84 & 0.012 \\
\hline 40.00 & 0.14 & 0.020 & 0.61 & 0.020 & 0.68 & 0.020 & 0.72 & 0.022 \\
\hline \multicolumn{9}{|c|}{ 1-Pentanol (1) + Ethyl octanoate (2) } \\
\hline 15.00 & 0.32 & 0.003 & 1.50 & 0.008 & 0.96 & 0.004 & 1.54 & 0.009 \\
\hline 40.00 & 0.59 & 0.008 & 1.00 & 0.004 & 0.94 & 0.004 & 1.13 & 0.010 \\
\hline
\end{tabular}

$\Delta T / K=\sum_{k=1}^{N}\left|T_{k}^{e x p}-T_{k}^{c a l}\right| / N ; \Delta y_{1}=\sum_{k=1}^{N}\left|y_{i k}^{e x p}-y_{i k}^{c a l}\right| / N$. 

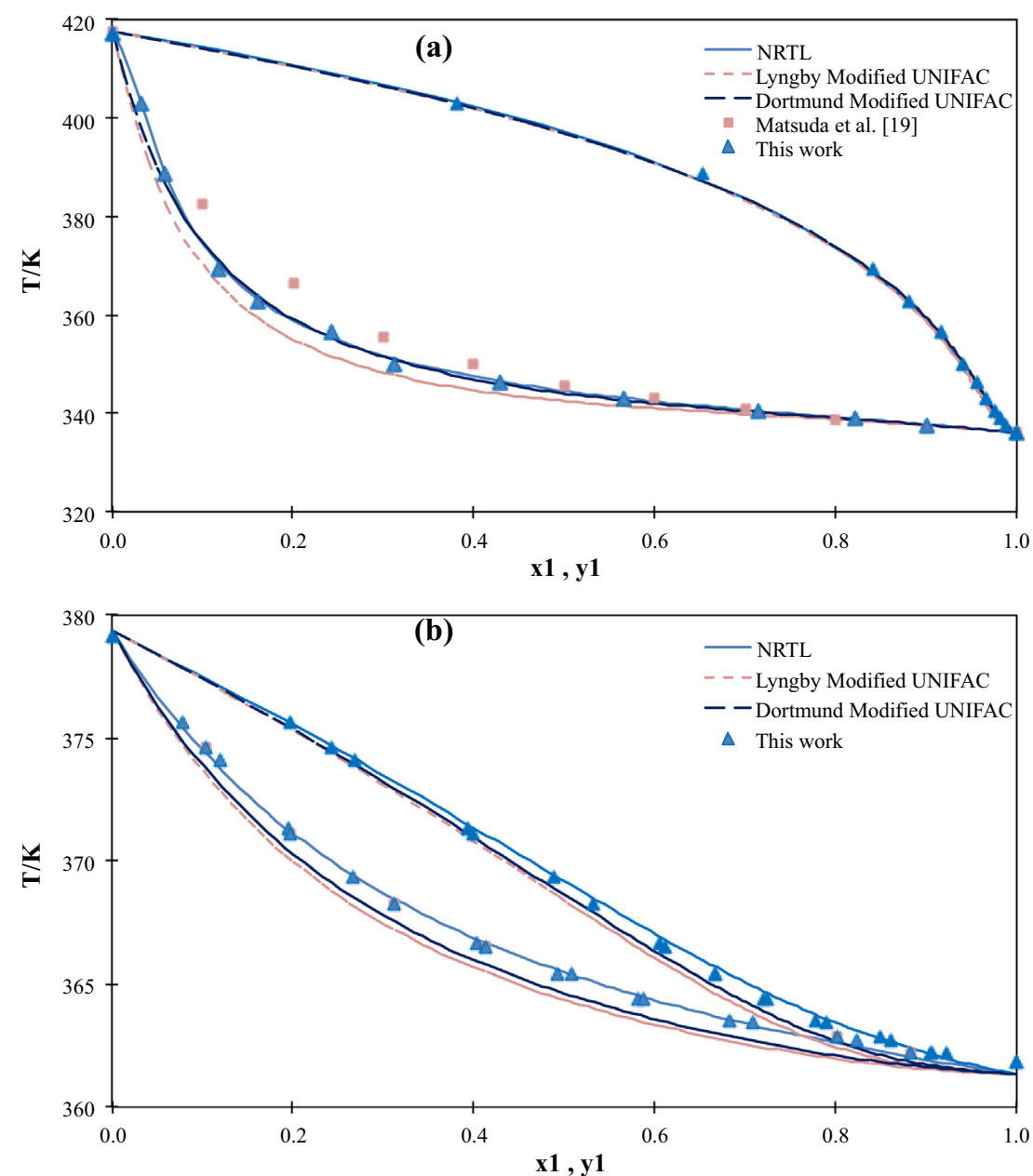

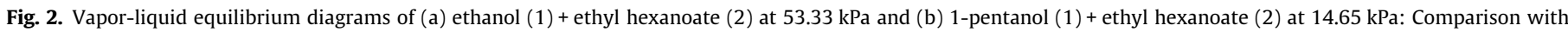
Matsuda et al. [19] and modeling performances.

a solvation scheme involving combining rules for the crossassociation energy and leaving the cross-association volume $\left(\beta_{i j}\right)$, along with the binary interaction parameter $\left(k_{i j}\right)$, as an adjustable parameter. In that work it was possible to infer that the crossassociation volume parameter can be kept constant, around 0.1 , while the binary interaction parameter is regressed from experimental data. For ethanol systems it is also possible to establish a linear correlation for the binary interaction parameter with the ester carbon number. The same approach is followed in this work: a cross-association volume of 0.1 was applied for all the systems, for the ethanol + ethyl hexanoate system the binary interaction parameter was computed from the linear correlation established in a previous work [37], and for the remaining systems, the binary interaction parameters were regressed from the experimental VLE data at both pressures. The corresponding parameter values are presented at Table S9 (SM7), while the model performance can also be seen in Table 6.

Fig. 3 compares the performance of the three predictive approaches used. In fact, as CPA EoS is concerned, the only binary system for which the results are pure prediction is the system ethanol + ethyl hexanoate. While the dew curve is the same between different models, UNIFAC-Do predicts much better the boiling curve as can be confirmed by the deviations presented in Table 6.

Fig. 4 compares the results from UNIFAC-Do and CPA for systems (a) 1-pentanol + ethyl hexanoate at $40.00 \mathrm{kPa}$, and (b) 1pentanol + ethyl octanoate at $15 \mathrm{kPa}$. Both approaches present very similar and satisfactory results. In Fig. 4b is evident the difference in the boiling temperature of ethyl octanoate, which is related to the type of model used. Applying CPA EoS, the vapor pressure is calculated within the model, while with UNIFAC vapor pressure is calculated in accordance to Eq. (1) with coefficients of Table S4 (SM4), giving rise to such differences.

\subsection{Multicomponent systems: Data and modeling}

The multicomponent system here studied is a mixture of BAEEs with 1-octanol and 1-dodecanol, and the VLE measurements were conducted at 8,10 and $12 \mathrm{kPa}$. In total 12 runs were carried out within a temperature range between $447 \mathrm{~K}$ and $472 \mathrm{~K}$. Technical limitations to attain equilibrium in such complex mixtures imposed the selection of the composition of the charge to the ebulliometer as well as pressure and temperature ranges. Table S10 (SM8) compiles the collected data.

In order to test the performance of the predictive approaches, UNIFAC-Do and CPA were used to calculate the compositions of both phases at given pressure and temperature. In that regard, within CPA, data were difficult to find and so assumptions had to be made in order to establish binary interaction parameters: no binary interaction parameters were assigned for alcohol-alcohol and ester-ester binaries. For alcohol-ester, since the previous calculations with ethyl hexanoate and 1-pentanol, or ethanol, the regressed $k_{i j}$ was almost the same it suggests that for longer alcohols this value might become constant. So the value of $k_{i j}$ for 


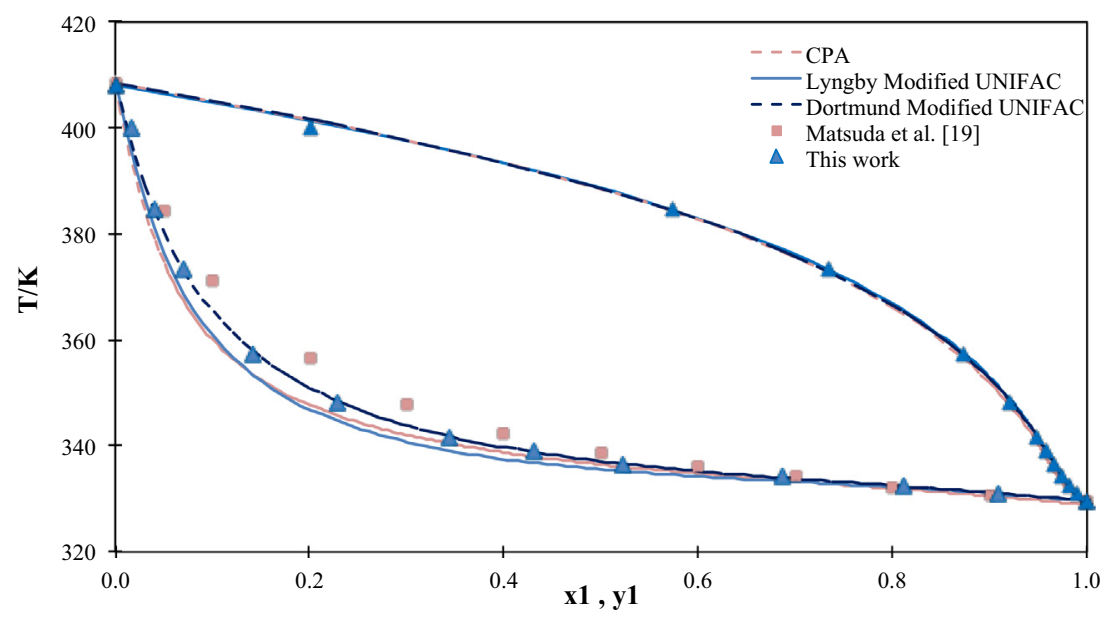

Fig. 3. Vapor-liquid equilibrium diagrams of ethanol (1) + ethyl hexanoate (2) at $40.00 \mathrm{kPa}$ : Comparison with Matsuda et al. [19] and between predictive models.
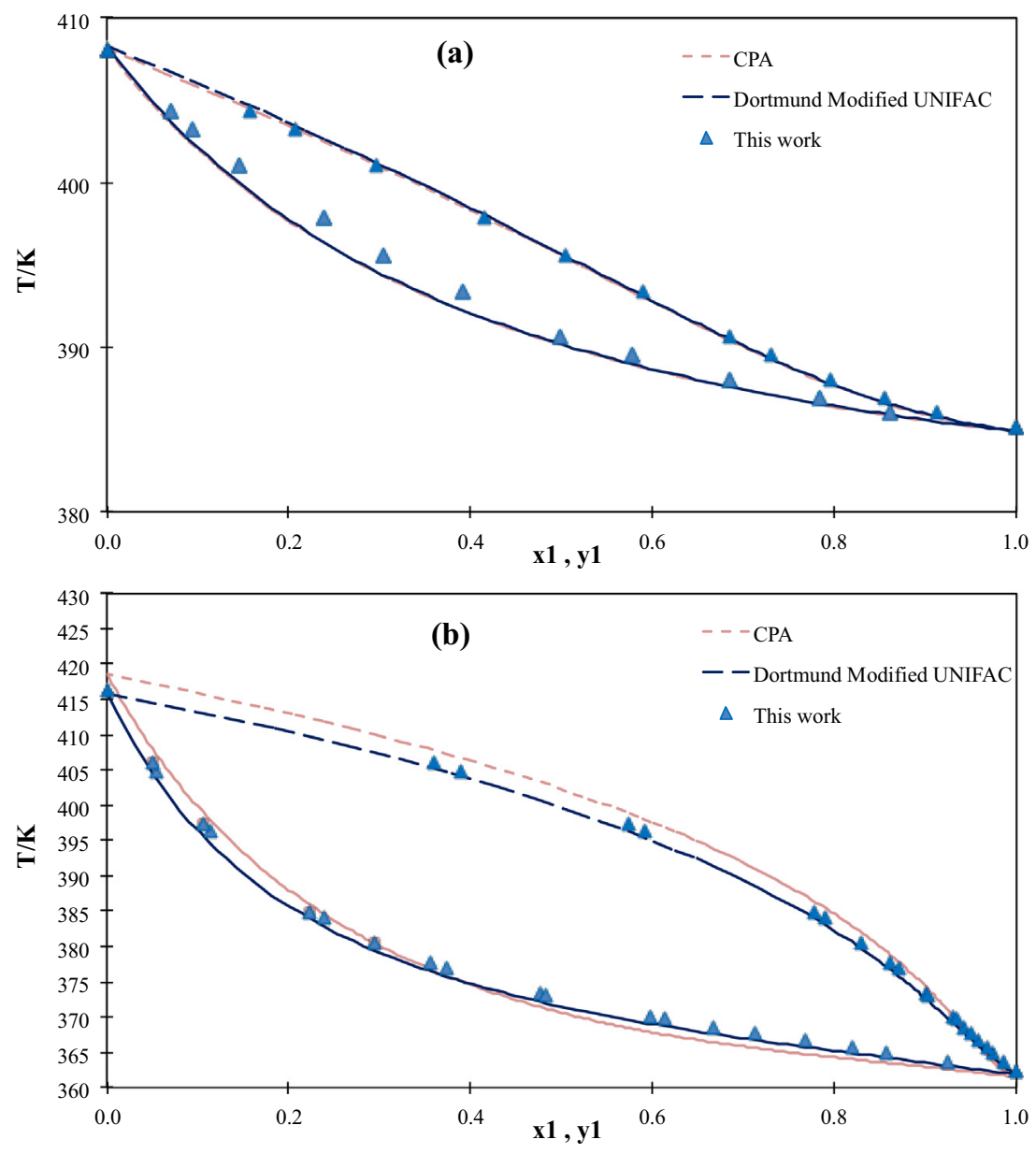

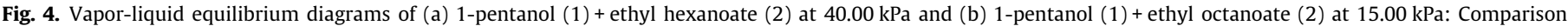
UNIFAC-Do and CPA.

the 1-pentanol-ethyl hexanoate system was selected for the binaries 1 -octanol-ester and 1-dodecanol-ester. The parameter $\beta_{i j}$ was kept equal to 0.1 as typically done for alcohol-ester systems.

Fig. 5 makes a global comparison between the UNIFAC-Do and CPA predictions concerning the deviations in the liquid $\left(\Delta x=x^{\exp }-x^{\text {calc }}\right)$ and vapor phase mole fraction $\left(\Delta y=y^{\exp }-y^{\text {calc }}\right)$, neglecting ethyl cis-vaccenate and ethyl arachidate, which are infinitely diluted in the charge. Generally, the deviations with CPA are smaller than with UNIFAC-Do, what can be related to the fact that CPA itself represents the vapor pressure of the pure compounds. However, while for liquid compositions the deviations are very small for all compounds, those are much more pronounced for the alcohol vapor phase composition. Curiously, UNIFAC-Do underestimates the composition of 1-octanol in the vapor phase, while 


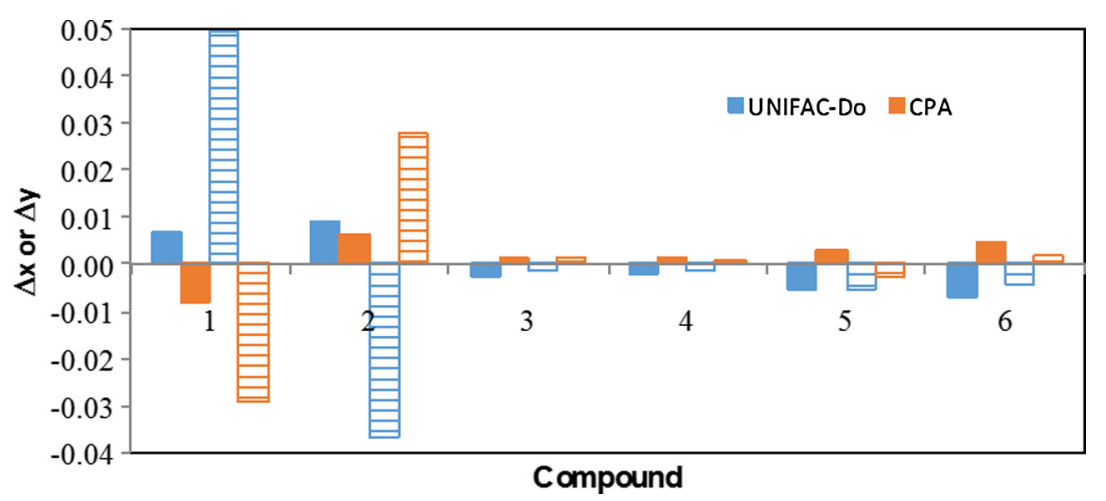

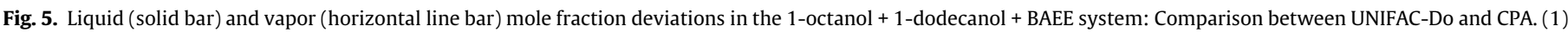
1-octanol, (2) 1-dodecanol, (3) ethyl palmitate, (4) ethyl stearate, (5) ethyl oleate and (6) ethyl linoleate.

the CPA EoS overestimates it, occurring the opposite situation with1-dodecanol.

In more detail Table S11 (SM8) presents the global deviations for each set. Globally, both methods predict quite well the mole fraction composition in the liquid phase, while for the vapor phase deviations are more pronounced. Within UNIFAC-Do deviations are very uniform, while with CPA deviations in the vapor phase mole fraction increases with the concentration of BAEEs in the charge increases.

\section{Conclusions}

The vapor pressures of ethyl hexanoate and ethyl octanoate have been measured in the temperature range between 359.5 and $473.1 \mathrm{~K}$. The quality of the data was checked and new data increases considerably the information available for the two pure compounds. The complete PTxy phase diagram for binary systems ethanol + ethyl hexanoate, 1-pentanol + ethyl hexanoate and 1pentanol + ethyl octanoate at two different pressures are reported for the first time. Consistency tests showed quality factors much higher than those usually found for the same class of systems.

Concerning modeling, NRTL with temperature dependent interaction parameters showed a very good performance for correlating the data, but the very satisfactory accuracy of the modified UNIFAC (Dortmund) in the prediction of the phase diagrams must be stressed, where average deviations in temperature and vapor compositions were $0.76 \mathrm{~K}$ and 0.010 , respectively. Finally, the CPA EoS with a unique estimated parameter showed also very high precision in the description of these particular complex systems. The two methods proved also to be very satisfactory in the prediction of the phase composition in a multicomponent system containing Balanites aegyptiaca fatty acid ethyl esters, 1-octanol and 1dodecanol.

\section{Acknowledgements}

This work was developed in the scope of the Projects POCI-010145-FEDER-006984 - Associate Laboratory LSRE-LCM and POCI01-0145-FEDER-007679 - CICECO-Aveiro Institute of Materials (FCT Ref. UID/CTM /50011/2013), funded by FEDER (European Union) through COMPETE2020 - Programa Operacional Competitividade e Internacionalização (POCI) - and by national funds through FCT (Portugal) - Fundação para a Ciência e a Tecnologia. Also, the authors express their acknowledgment to Frédéric Roze from Université de Lorraine - ENSIC (France) for his technical support during the work.

\section{Appendix A. Supplementary data}

Supplementary data associated with this article can be found, in the online version, at http://dx.doi.org/10.1016/j.fuel.2017.05.007.

\section{References}

[1] Borugadda VB, Goud VV. Biodiesel production from renewable feedstocks: status and opportunities. Renewable Sustainable Energy Rev 2012;16:4763-84.

[2] Coniglio L, Coutinho JAP, Clavier JY, Jolibert F, Jose J, Mokbel I, et al. Biodiesel via supercritical ethanolysis within a global analysis "Feedstocks-conversionengine" for a sustainable fuel alternative. Prog Energy Combust Sci 2014; $43: 1-35$

[3] Cunico LP, Ceriani R, Sarup B, O’Connell JP, Gani R. Data, analysis and modeling of physical properties for process design of systems involving lipids. Fluid Phase Equilib 2014;362:318-27.

[4] Thi TXN, Tamouza S, Tobaly P, Passarello JP, de Hemptinne JC. Application of group contribution SAFT equation of state (GC-SAFT) to model phase behaviour of light and heavy esters. Fluid Phase Equilib 2005;238:254-61.

[5] NguyenHuynh D, Falaix A, Passarello JP, Tobaly P, de Hemptinne JC. Predicting VLE of heavy esters and their mixtures using GC-SAFT. Fluid Phase Equilib 2008;264:184-200.

[6] Nitièma-Yefanova S, Richard R, Roux ST, Bouyssiere B, Coulibaly YLB, Nébié RHC, et al. Dry purification by natural adsorbents of ethyl biodiesels derived from nonedible oils. Energy Fuels 2015;29:150-9.

[7] Nitièma-Yefanova S, Coniglio L, Schneider R, Nébié RHC, Bonzi-Coulibaly YL. Ethyl biodiesel production from non-edible oils of Balanites aegyptiaca, Azadirachta indica, and Jatropha curcas seeds - laboratory scale development. Renewable Energy 2016;96:881-90.

[8] Nitièma-Yefanova S, Tschamber V, Richard R, Thiebaud-Roux S, Bouyssiere B, Bonzi-Coulibaly YL, et al. Ethyl biodiesels derived from non-edible oils within the biorefinery concept - pilot scale production \& engine emissions. Renewable Energy 2017;109:634-45.

[9] EN-14103. Fat and oil derivatives, fatty acid methyl esters (FAME), determination of ester and linoleic acid methyl ester contents. Brussels (Belgium): European Committee for Standardization; 2003.

[10] http://www.pignat.com.

[11] Rowley RL, Wilding WV, Oscarson JL, Knotts TA, Iles NF. DIPPR 801 data compilation of pure chemical properties; design institute for physical properties. AIChE: New York, NY; 2015.

[12] Constantino DSM, Pereira CSM, Pinho SP, Silva VMTM, Rodrigues AE. Isobaric vapor-liquid equilibrium data for binary system of glycerol ethyl acetal and acetonitrile at 60.0 and $97.8 \mathrm{kPa}$. J Chem Eng Data 2013;58:1717-23.

[13] Casimiro FM, Constantino DSM, Pereira CSM, Ferreira O, Rodrigues AE, Pinho SP. Vapor-liquid equilibrium of binary mixtures containing isopropyl acetate and alkanols at $101.32 \mathrm{kPa}$. J Chem Eng Data 2015;60:3181-6.

[14] Dortmund Data Bank, DDBST GmbH. In Oldenburg, Germany; 2017.

[15] Wilsak RA, Thodos G. Critical assessment of four vapor pressure functions over the complete vapor-liquid coexistence region. Ind Eng Chem Fundam $1984 ; 23: 75-82$.

[16] Bureau N, Jose J, Mokbel I, de Hemptinne JC. Vapor pressure measurements and prediction for heavy esters. J Chem Thermodyn 2001:33:1485-98.

[17] Plyasunov AV, Plyasunova NV, Shock EL. Group contribution values for the thermodynamic functions of hydration of aliphatic esters at 298.15 K, 0.1 MPa. J Chem Eng Data 2004;49:1152-67.

[18] Benziane M, Khimeche K, Mokbel I, Sawaya T, Dahmani A, Jose J. Experimental vapor pressures of five saturated fatty acid ethyl ester (FAEE) components of biodiesel. J Chem Eng Data 2011;56:4736-40. 
[19] Matsuda H, Yamada H, Takahashi R, Koda A, Kurihara K, Tochigi K, et al. Ebulliometric determination and prediction of vapor-liquid equilibria for binary mixtures of ethanol and ethyl hexanoate. J Chem Eng Data 2011;56:5045-51.

[20] Leyva F, Orjuela A, Gil I, Vargas J, Rodríguez G. Vapor-liquid equilibrium of isoamyl alcohol + isoamyl propionate and propionic acid + isoamyl propionate systems at 50.00, 101.33 and $150.00 \mathrm{kPa}$. Fluid Phase Equilib 2013;356:56-62.

[21] Kang JW, Diky V, Chirico RD, Magee JW, Muzny CD, Abdulagatov I, et al. Quality assessment algorithm for vapor-liquid equilibrium data. J Chem Eng Data 2000;55:3631-40

[22] Kang JW, Diky V, Chirico RD, Magee JW, Muzny CD, Kazakov AF, et al Algorithmic framework for quality assessment of phase equilibrium data. J Chem Eng Data 2000;59:2283-93.

[23] Herington EFG. Tests for the consistency of experimental isobaric vapor-liquid equilibrium data. J Inst Pet 1951;37:457-70.

[24] Kojima K, Moon MH, Ochi K. Thermodynamic consistency test of vapor-liquid equilibrium data. Fluid Phase Equilib 1990;56:269-84.

[25] Kurihara K, Egawa Y, Ochi K, Kojima K. Evaluation of thermodynamic consistency of isobaric and isothermal binary vapor-liquid equilibrium data using the PAI test. Fluid Phase Equilib 2004;219:75-85.

[26] Van Ness HC, Byer SM, Gibbs RE. Vapor-liquid equilibrium: Part I. An appraisa of data reduction methods. AIChE J 1973;19:238-44.

[27] Renon H, Prausnitz JM. Local compositions in thermodynamic excess functions for liquid mixtures. AIChE J 1968;14:135-44.

[28] Larsen BL, Rasmussen P, Fredenslund A. A modified UNIFAC groupcontribution model for prediction of phase equilibria and heats of mixing. Ind Eng Chem Res 1987;26:2274-86.
[29] Weidlich U, Gmehling J. A modified UNIFAC model. 1. Prediction of VLE, hE, and $\gamma_{\infty}$. Ind Eng Chem Res 1987;26:1372-81.

[30] Gmehling J, Li J, Schiller M. A modified UNIFAC model. 2. Present parameter matrix and results for different thermodynamic properties. Ind Eng Chem Res 1993;32:178-93.

[31] Gmehling J, Lohmann J, Jakob A, Li J, Joh R. A modified UNIFAC (Dortmund) model. 3. Revision and extension. Ind Eng Chem Res 1998;37:4876-82.

[32] Lohmann J, Gmehling J. Modified UNIFAC (Dortmund): reliable model for the development of thermal separation processes. J Chem Eng Jpn 2001:34:43-54.

[33] Gmehling J, Wittig R, Lohmann J, Joh R. A modified UNIFAC (Dortmund) model. 4. Revision and extension. Ind Eng Chem Res 2002;41:1678-88.

[34] Oliveira MB, Marrucho IM, Coutinho JAP, Queimada AJ. Surface tension of chain molecules through a combination of the gradient theory with the CPA EoS. Fluid Phase Equilib 2008;267:83-91.

[35] Oliveira MB, Varanda FR, Marrucho IM, Queimada AJ, Coutinho JAP. Prediction of water solubility in biodiesel with the CPA equation of state. Ind Eng Chem Res 2008;47:4278-85.

[36] Oliveira MB, Follegatti-Romero LA, Lanza M, Batista FRM, Batista EAC, Meirelles AJA. Low pressure vapor-liquid equilibria modeling of biodiese related systems with Cubic-Plus-Association (CPA) equation of state. Fuel 2014;133:224-31.

[37] Oliveira MB, Miguel SI, Queimada AJ, Coutinho JAP. Phase equilibria of ester + alcohol systems and their description with Cubic-Plus-Association equation of state. Ind Eng Chem Res 2010;49:3452-8. 